\title{
New concepts of the pathogenesis of cystic fibrosis lung disease
}

\author{
R.C. Boucher
}

New concepts of the pathogenesis of cystic fibrosis lung disease. R. C. Boucher. C) ERS Journals Ltd 2004.

ABSTRACT: Although there has been impressive progress in the elucidation of the genetic and molecular basis of cystic fibrosis $(C F)$, the pathogenesis of $C F$ lung disease remains obscure. The elucidation of the pathogenesis of $\mathrm{CF}$ lung disease requires both a full description of normal innate airway defence and how absent function of the cystic fibrosis transmembrane regulator protein (CFTR) adversely perturbs this activity.

Recent data have linked the abnormal ion transport properties of $\mathrm{CF}$ airway epithelia to depleted airway surface liquid (ASL) volume, reflecting the combined defects of accelerated $\mathrm{Na}^{+}$transport and the failure to secrete $\mathrm{Cl}^{-}$. Depletion of a specific compartment of the ASL, i.e. the periciliary liquid (PCL), appears to abrogate both cilia-dependent and cough clearance.

Subsequent to PCL depletion, mucus adheres to airway surfaces and persistent mucin secretion generates the formation of "thickened" mucus plaques and plugs, which become the nidus for bacterial infection. The paucity of liquid in these plaques/plugs, and the hypoxia in this environment, appear to promote biofilm bacterial infection.

Therapeutic agents that restore airway surface liquid volume, i.e. blockers of $\mathrm{Na}^{+}$ transport, initiators of $\mathrm{Cl}^{-}$transport and osmolytes, are reviewed, as are strategies that may be required to use volume-restoring agents safely in patients with cystic fibrosis. Eur Respir J 2004; 23: 146-158.
Correspondence: R.C. Boucher

Cystic Fibrosis/Pulmonary Research and Treatment Center

7011 Thurston-Bowles Building, CB\# 7248

The University of North Carolina

at Chapel Hill

Chapel Hill

NC 27599

USA

Fax: 19199661077

E-mail: rboucher@med.unc.edu

Keywords: Biofilms

mucus adhesion

mucus hypoxia

perciliary liquid

volume replenishment

Received: May 222003

Accepted: July 162003
There has been immense progress in the elucidation of the molecular and cellular pathophysiology of cystic fibrosis (CF) since the cloning of the CF gene in 1989 [1-3]. Despite this progress, the median life-span of $\mathrm{CF}$ patients at the turn of the century was $\sim 32$ yrs of age [4], and the great majority of $\mathrm{CF}$ patients die from lung disease. This review will touch briefly on the wealth of information on the genetics and cell biology of $\mathrm{CF}$ as it pertains to lung disease, and concentrate its focus on recent studies that have provided a more comprehensive delineation of the pathogenesis of CF airways disease and consequently opened new avenues for therapy. For more extensive reviews of the genetics and cell biology of $\mathrm{CF}$, the reader is referred to previous reviews $[5,6]$.

\section{The genetics of cystic fibrosis}

The cystic fibrosis transmembrane regulator (CFTR) gene is a large, $\sim 250 \mathrm{~kb}$, gene that is located on the long arm of chromosome 7 . To date, $>1,000$ candidate mutations in the $\mathrm{CF}$ gene have been identified and reported to the $\mathrm{CF}$ Gene Mutation Consortium in Toronto, ON, Canada [7]. The large number of different mutations has made population screening for $\mathrm{CF}$ problematic, but genetic diagnosis is now practical for counselling parents with one affected CF child.

An important area of $\mathrm{CF}$ research has focused on the topic of genotype-phenotype prediction $[8,9]$. In brief, it has been possible to predict the severity of the CF organ-level phenotype from the genotype with high fidelity with respect to the sweat duct, pancreas, and the reproductive system. In contrast, it has been difficult to identify correlations between genotype and phenotype of lung disease, i.e. severity. This difficulty is perhaps best illustrated by the fact that patients who are homozygous for the $\Delta \mathrm{F} 508$ mutation exhibit a wide spectrum in the rate of development and severity of lung disease $[10,11]$.

The failure to generate genotype-phenotype predictions in the lung has led to the notion that both environmental-lung interactions and the genetic background of the host contribute substantially to the severity of CF lung disease. With respect to the latter concept, a search has been initiated for "modifier genes", i.e. genes that modify the effect of $\mathrm{CF}$ mutations on lung dysfunction. At present, a number of modifier genes have been identified, based on "candidate selection" [12-17]. Thus far, these genes appear to include those that regulate aspects of innate lung defence and inflammatory cascades. The next level of studies designed to identify modifier genes will involve genome-wide searches, using single nucleotide polymorphisms, in an effort to identify novel genes that contribute to the severity of CF lung disease $[18,19]$. Finally, it is likely that the genome-wide searches will soon be complemented by proteomic approaches designed to elucidate proteins that function as modifiers. A great hope is that these studies ultimately will identify key genes and proteins that may be rational therapeutic targets, i.e. their functions could be accelerated or decelerated as indicated.

\section{The cell biology of cystic fibrosis}

CF reflects the absence of functional CFTR protein at the proper cellular location [20]. Classifications of CFTR mutations have been developed that encompass the spectrum of genetic mutations, but the majority appear to involve 
misfolding of CFTR protein. The most common CF mutation, $\Delta \mathrm{F} 508$, was the first to be shown to exhibit a problem in polypeptide maturation and translocation to the appropriate cellular domain, e.g. the apical membrane [21]. Although the experiments in heterologous cell systems are elegant and demonstrate unequivocally a misfolding problem with the $\Delta F 508$ CFTR protein, the extent of misfolding and failure of translocation to the apical cell domain in patients homozygous for $\triangle F 508$ CFTR is still controversial. For example, whereas the evidence appears strong that virtually all $\Delta \mathrm{F} 508$ CFTR fails to translocate to the apical membrane of the sweat duct [22], there are reports that a substantial fraction of the $\Delta \mathrm{F} 508$ protein translocates to the apical membrane in the airways and colonic epithelium, as assessed by combinations of immunocytochemical, Western blot and biophysical studies $[23,24]$. Others, however, have not been able to reproduce this result $[25,26]$. As it is likely that $\Delta \mathrm{F} 508$ protein exhibits $\sim 30 \%$ of wildtype activity when fully stimulated $[27,28]$, and hence would be a logical therapeutic target, it is important to resolve the issue of whether $\Delta \mathrm{F} 508$ is in the apical membranes of airway and colonic epithelia in vivo with newer high-affinity antibodies that may be suited to resolve this difficult question.

\section{Organ-level pathogenesis of cystic fibrosis: a disease of abnormal innate lung defence}

CF patients are born with apparently normal lungs, followed by the acquisition of chronic, unrelenting bacterial infections of the airways (bronchi) in the first few years of life. Thus, in the simplest view, CF lung disease reflects the failure of the innate defence mechanisms of the lung against inhaled bacterial organisms [29]. The recognition of this general problem has led to studies designed to elucidate the normal innate defences against inhaled bacteria and how these defences may be degraded by the absence of functional CFTR.

As described in figure la, two hypotheses have been developed to link epithelial ion transport to the innate defence of airways against inhaled bacterial pathogens. In perhaps the more classical schema, mechanical clearance has been viewed as the primary innate defence against inhaled bacterial species. Mucus clearance provides the mechanical clearance that removes bacteria from the airways in $\leqslant 6 \mathrm{~h}$ under normal conditions [30]. It would appear that there are sufficient antimicrobial activities, provided by lactoferrin and lysozyme, to suppress bacterial growth over these time frames [31]. As described in detail below, the promotion of efficient mucus transport requires an elegant coordination of intertwined physiological events that, in the end, provide a welldefined periciliary liquid (PCL) layer that exhibits an optimal height $(\sim 7 \mu \mathrm{m}$, i.e. the height of extended cilia) and viscosity for effective ciliary beating and cell surface lubrication (fig. 1b). The capacity of the epithelium to maintain the PCL layer at the appropriate height requires the adjustment of airway surface liquid (ASL) volume, a process that is believed to be mediated by isotonic $(100-150 \mathrm{mM} \mathrm{NaCl})$ volume transport [32-34].

In the early to mid-1990s, a novel hypothesis for airways' defence emerged that focused on the role of antimicrobial peptides in ASL to provide a chemical shield on the airway surface as the primary innate defence [35-37]. For this shield to be effective, two processes must be normally regulated by the airway epithelium. First, there must be secretion of the appropriate quantities of antimicrobial, salt-sensitive peptides (defensins), and secondly, the ASL must be modified, i.e. made hypotonic $(>50 \mathrm{mM} \mathrm{NaCl})$, so antimicrobials are active.

Although there have been many studies designed to explore a)

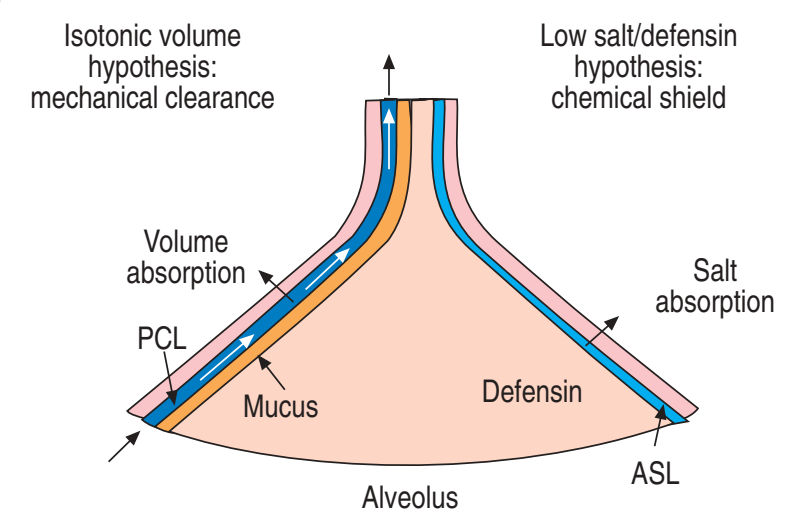

b)

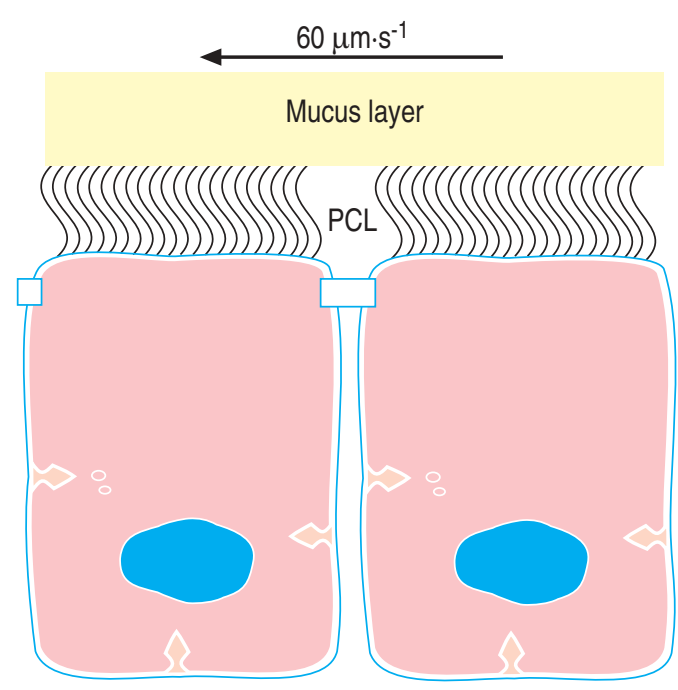

Fig. 1.- Models depicting elements of innate airways defense. a) Model depicting relative surface areas of distal and proximal airway regions. On the left is the depiction of the mechanical (mucus) clearance hypothesis, with the epithelium controlling the volume of the periciliary liquid (PCL) as the critical element mediating efficient mucus transport. On the right is shown the chemical shield hypothesis that predicts that the airways epithelium absorbs salt but not water from airway surface liquid (ASL) to form a "low salt" ASL to promote antimicrobial activities of defensins. b) Schema of airway surface liquid compartment depicting mucus layer, PCL and normal velocity of mucus transport.

the relative merits of each hypothesis, particularly in model systems, perhaps the simplest approach is to test in vivo the concentrations of the relevant antimicrobial factors and their salt sensitivities, and most importantly, perhaps, the ionic composition of normal ASL. With respect to antimicrobial activities, the studies of COLE et al. [31] identified lactoferrin and lysozyme in airway surface liquids as the major antimicrobial substances, in concentrations that rendered them relatively salt-insensitive. In contrast, it has been difficult to identify small molecular weight defensin-like molecules in ASL, nor identify any defensin-like antimicrobial activity in the presence of human airway mucins.

With respect to ASL ionic composition, virtually all of the recent in vivo data have suggested that ASL in normal subjects is indeed isotonic. For example, human ASL has been measured in the upper and lower airways with a variety of techniques, including filter paper and ion-selective electrodes, and is isotonic [38, 39]. $\mathrm{Cl}^{-}$ion-selective electrode measurements have shown that the ASL in primates is isotonic from the upper airways to the bronchioles [39]. These studies have been complemented by studies using other techniques, e.g. 
fluorescent probes and in vivo microdialysis, in normal mice, which revealed an isotonic ASL. These studies add to a spectrum of older studies of ASL ion composition from a variety of normal mammals, including dog, sheep and pigs, which also revealed isotonic ASL [34]. Finally, despite the predictions of the defensin/low salt hypothesis, measurements of ASL ionic composition comparing uninfected $\mathrm{CF}$ and normal human subjects and normal and CF mice have failed to detect differences in ASL ion composition, i.e. both normal and CF ASL are isotonic [32, 38, 40-42]. Thus, it appears that the weight of the evidence would favour an isotonic liquid on normal airway surfaces, which strongly favours the mechanical clearance hypothesis [43-45].

\section{The normal regulation of airway surface liquid clearance: processes designed to maintain an intact periciliary liquid layer}

The ability to study the $\sim 30 \mu \mathrm{m}$ deep ASL, and study of the physiology of its component mucus and PCL layers, has been greatly buttressed by the availability of well-differentiated airway epithelial cultures. These cultures secrete mucins, transport salt and water, and organise ciliary beat direction so that the integrated function of surface (rotational) mucus transport is expressed in vitro [46] (fig. 2). The different compartments of these cultures can be labelled with fluorescent probes and studied as living cultures in the confocal microscope. This system thus offers unique opportunities to investigate the integrated physiology of epithelial salt and water transport, mucin secretion and ciliary beating. Indeed, studies with this system revealed that both components of ASL, i.e. the mucus and PCL layers, are transported at approximately equal rates along airway surfaces via the actions of cilia [46].

The mucus layer serves to trap inhaled material during the clearance process from the airways. The mucus layer uses two mechanisms to remove virtually all inhaled particles that deposit on airway surfaces: 1) mucus flow is "turbulent", so materials are mixed into the mucus layer and enmeshed/ trapped during clearance [48]; and 2) mucin molecules exhibit a "combinatorial library" of carbohydrate epitopes to ensure low affinity binding to most particles [49]. However, a less recognised role of the mucus layer in mucus transport reflects its reservoir-like capacity to store and release liquid, i.e. swell and shrink [33]. This passive process is of enormous importance in maintaining PCL volume by donating to or accepting liquid from the PCL layer as needed. Thus, it appears that when there is a relative depletion of liquid on airway surfaces, the mucus layer donates liquid until its height/volume is reduced $\sim 50 \%$ before its capacity to donate liquid is exceeded and detectable depletion of PCL height/volume occurs. Conversely, it appears that extra liquid added to the airway surface does not expand the PCL layer, but rather is selectively added to the mucus layer, "swelling" it. Interestingly, the addition of extra fluid to the mucus layer appears not only to maintain mucus clearance, but also to accelerate it [33].

The contribution of active epithelial ion transport to ASL and PCL volume regulation has been studied in similar systems [33]. As shown in figure 3a, the human airway ciliated epithelial cell expresses the epithelial $\mathrm{Na}^{+}$channels $(\mathrm{ENaC})$ and pumps $\left(\mathrm{Na}^{+} / \mathrm{K}^{+}\right.$-ATPase $)$to mediate transcellular $\mathrm{Na}^{+}$ absorption. The ciliated cell also has the capacity, via expression of apical $\mathrm{Cl}^{-}$channels (CFTR and $\mathrm{Ca}^{2+}$-activated $\mathrm{Cl}^{-}$channels) and the basolateral $\mathrm{Na}^{+}-\mathrm{K}^{+}-2 \mathrm{Cl}^{-}$cotransporter, to secrete $\mathrm{Cl}^{-}$when $\mathrm{ENaC}$ is blocked and the appropriate $\mathrm{Cl}^{-}$secretory driving forces are generated. The importance of the capacity to both absorb and secrete is revealed in the processes that maintain PCL height (volume). As shown in figure $3 \mathrm{~b}$, it appears that "excess" ASL is absorbed until a steady state is achieved at approximately the height of the extended cilium, i.e. $7 \mu \mathrm{m}$, the normal PCL layer height. This regulation is complex and involves both sensors that detect the volume of ASL and effectors that control the rates of volume absorption and perhaps secretion. Unfortunately, relatively little is known about the sensors of ASL volume and how these sensors transmit information to the various effectors (ion channels) in the apical cell membrane. It may be that there are redundant sensor systems, some sensing chemical information encoded in the ASL, and others sensing mechanical properties (e.g. viscosity) of the ASL.

It is perhaps more clear what are the effectors that regulate the volume of ASL in response to the surface environment. For example, the volume absorptive process that removes excess liquid from airway surfaces is mediated by transepithelial $\mathrm{Na}^{+}$transport $[50,51]$ (fig. 3c). It appears that ENaC is highly active when ASL volume is large, whereas $\mathrm{ENaC}$ is inhibited when ASL volume approaches that of the normal PCL volume. When ENaC is inhibited, the electrical driving forces for initiating $\mathrm{Cl}^{-}$secretion are developed. Thus, the steady state PCL is likely maintained by a balance between $\mathrm{Na}^{+}$absorption and $\mathrm{Cl}^{-}$secretion. Recent studies have shown that the $\mathrm{Cl}^{-}$secretion induced by ENaC inhibition is mediated by CFTR, and that the level of CFTR activity is governed by signals in the lumenal bath, e.g. adenosine, interacting with compartmentalised adenosine receptors $A_{2 b}, G$ proteins $\left(G_{s}\right)$, adenylate cyclase, and cyclic adenosine monophosphate (cAMP)-dependent protein kinases [52]. Thus, it is speculated that the signal transduction pathways and effectors that control on a minute-to-minute basis the volume of ASL may be located in the apical domain of the cell.

\section{Cystic fibrosis airway surface liquid abnormalities: failure to "defend" the periciliary liquid layer}

Since the original detection of a raised potential difference (PD) across CF airway epithelia in vivo [53], there has been the notion that abnormal electrolyte transport is a key component of CF lung pathogenesis. Early PD studies detected an increase in the amiloride-sensitive component of the PD, which suggested an accelerated rate of $\mathrm{Na}^{+}$transport. However, the PD measurements also detected a failure to secrete $\mathrm{Cl}^{-}$ions, under basal conditions and $\beta$-adrenergic stimulation, which predicted a second defect [54].

Subsequent studies with freshly excised tissues and cultured cells established evidence for both $\mathrm{Na}^{+}$transport (upregulated) and $\mathrm{Cl}^{-}$transport (downregulated) defects in $\mathrm{CF}$ airway epithelia compared with normals. For example, radioisotope studies of active ion transport revealed accelerated $\mathrm{Na}^{+}$ transport under short-circuit and the more physiological open-circuit conditions [55-57]. The same technique revealed the absence of $\mathrm{Cl}^{-}$secretion under conditions when $\mathrm{ENaC}$ was blocked with amiloride under basal or $\beta$-agonist-stimulated conditions. Subsequent double-barrelled microelectrode studies of freshly excised and cultured normal and CF cells detected a raised apical membrane $\mathrm{Na}^{+}$conductance in $\mathrm{CF}$ cells and a reduced or absent $\mathrm{Cl}^{-}$conductance [58-61]. Ultimately, studies of the apical membrane channels with patch clamp techniques revealed an increased activity of $\mathrm{ENaC}$ (increased open probability) in CF compared with normal cells [62]. In summary, these studies suggested that the CFTR protein had dual functions in airway epithelia, i.e. to conduct $\mathrm{Cl}^{-}$ions and to regulate $\mathrm{ENaC}$. The absence of $\mathrm{CFTR}$ thus produces upregulation of $\mathrm{Na}^{+}$absorption and a failure of cAMPregulated $\mathrm{Cl}^{-}$secretion (fig. 4a).

Studies designed to describe the mechanisms of CFTR 

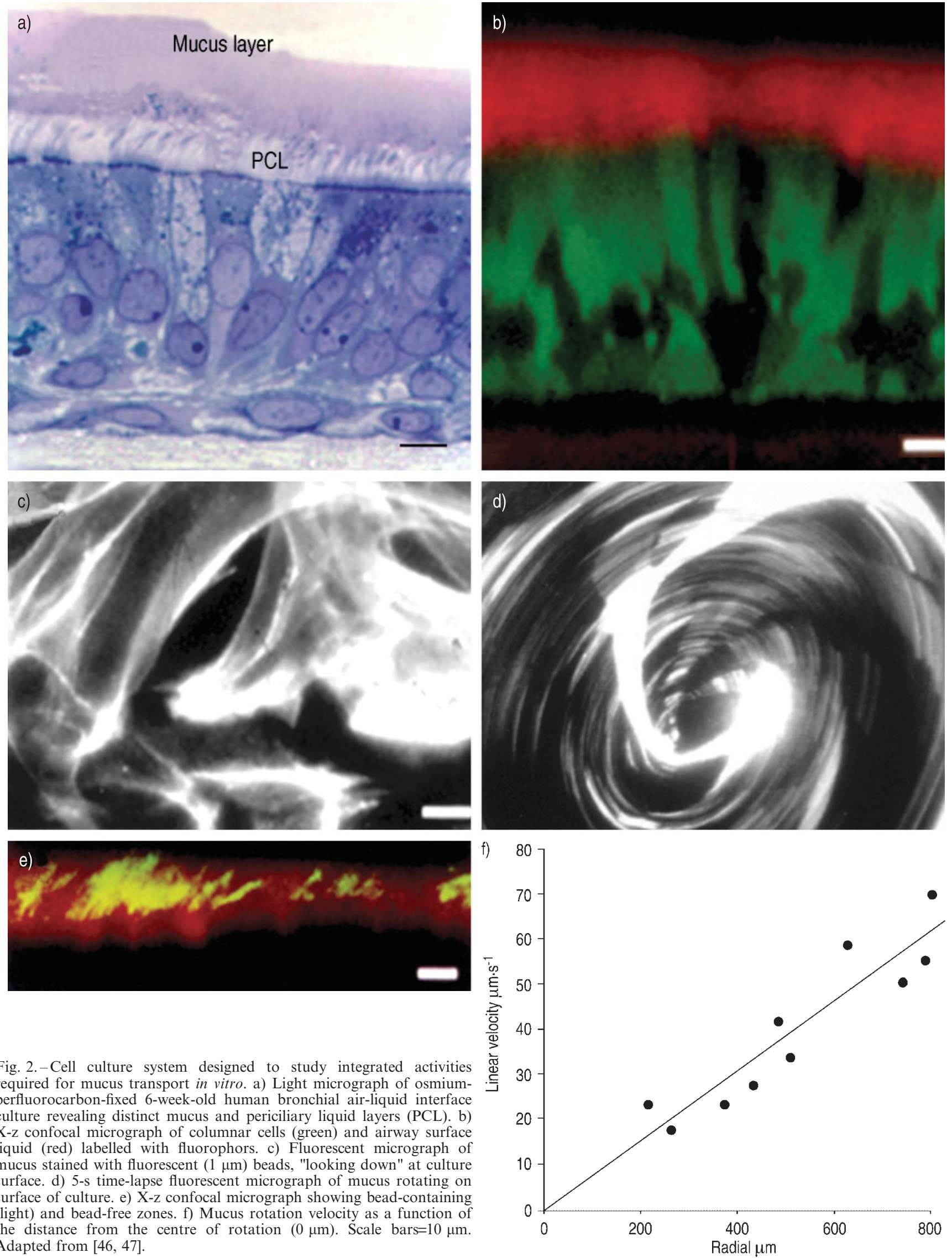

Fig. 2.-Cell culture system designed to study integrated activities required for mucus transport in vitro. a) Light micrograph of osmiumperfluorocarbon-fixed 6-week-old human bronchial air-liquid interface culture revealing distinct mucus and periciliary liquid layers (PCL). b) $\mathrm{X}-\mathrm{z}$ confocal micrograph of columnar cells (green) and airway surface liquid (red) labelled with fluorophors. c) Fluorescent micrograph of mucus stained with fluorescent $(1 \mu \mathrm{m})$ beads, "looking down" at culture surface. d) 5-s time-lapse fluorescent micrograph of mucus rotating on surface of culture. e) X-z confocal micrograph showing bead-containing (light) and bead-free zones. f) Mucus rotation velocity as a function of the distance from the centre of rotation $(0 \mu \mathrm{m})$. Scale bars $=10 \mu \mathrm{m}$. Adapted from $[46,47]$ 
a)

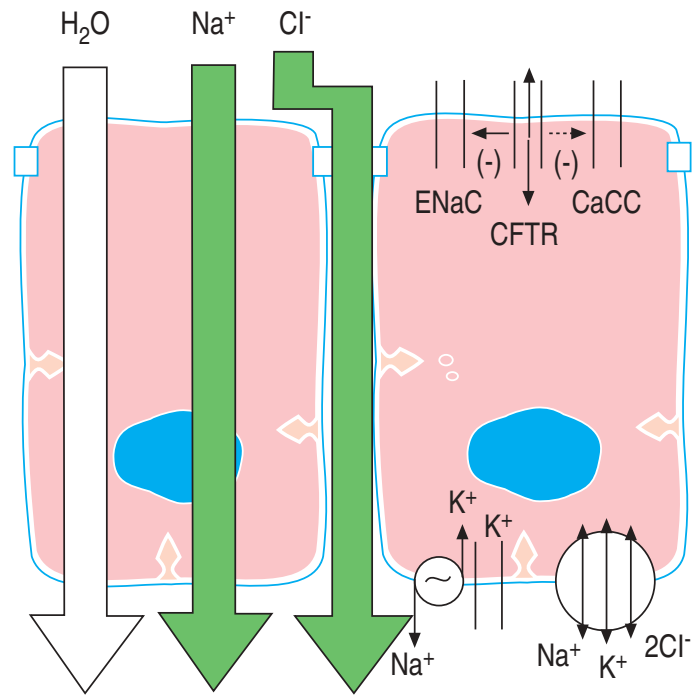

b)

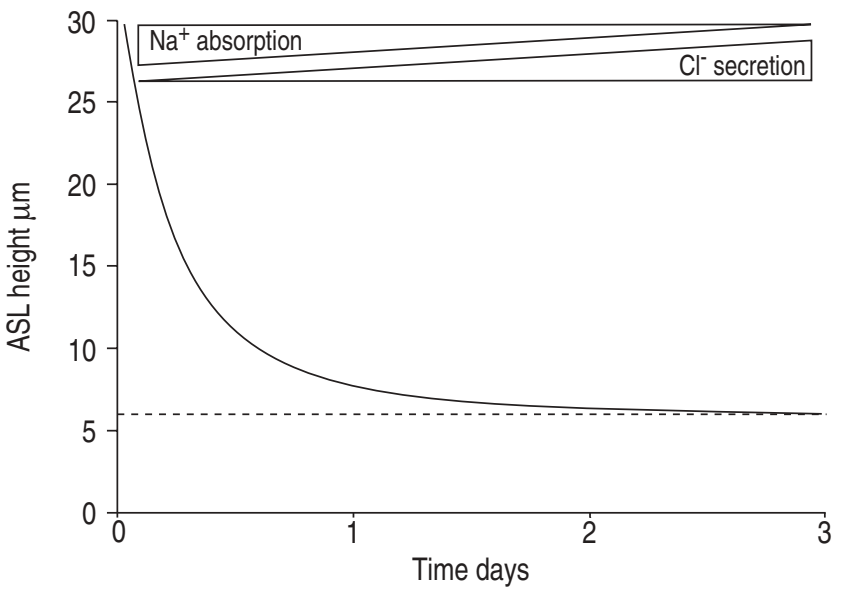

c)
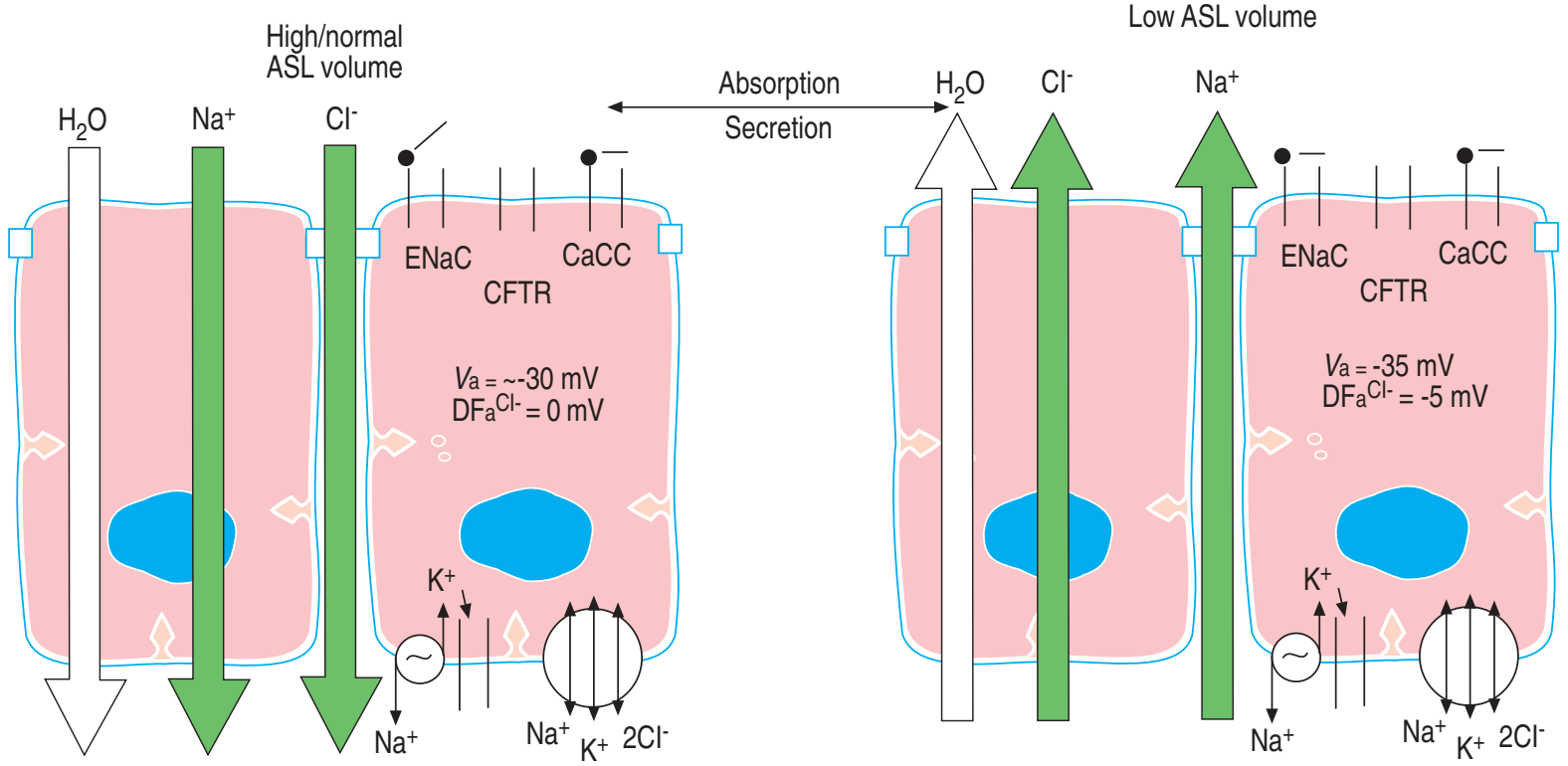

Fig. 3. - Regulation of the volume of periciliary liquid (PCL) layers by active ion transport. a) Schema describing routes of $\mathrm{Na}^{+}, \mathrm{Cl}^{-}$, and $\mathrm{H}_{2} \mathrm{O}$ transport and ion transport elements that mediate these flows. At the lumen are an epithelial $\mathrm{Na}^{+}$channel $(\mathrm{ENaC})$ and two $\mathrm{Cl}^{-}$channels: cystic fibrosis transmembrane regulator (CFTR) and the $\mathrm{Ca}^{2+}$-activated "alternative" $\mathrm{Cl}^{-}$channel (CaCC). CFTR is depicted as both a regulator of channels and as a $\mathrm{Cl}^{-}$channel itself. On the basolateral surface are the $\mathrm{Na}^{+} / \mathrm{K}^{+}$pump, the $\mathrm{K}^{+}$channels, and the loop diuretic sensitive $\mathrm{Na}^{+}-\mathrm{K}^{+}$$2 \mathrm{Cl}^{-}$cotransporter. b) Regulation of "excess" PCL volume by $\mathrm{Na}^{+}$absorption and maintenance of PCL at functionally relevant height $(7 \mu \mathrm{m}$ as defined by height of extended cilium), by a mix of the $\mathrm{Na}^{+}$absorption and $\mathrm{Cl}^{-}$secretion. c) Interconversion of normal human airway epithelia between absorptive and secretory ion transport modes. When excess airway surface liquid (ASL) is present, $\mathrm{Na}^{+}$absorption mediated via ENaC is dominant (left panel). $\mathrm{Cl}^{-}$is projected to be absorbed passively via the paracellular path due to the fact that there is no electrochemical driving force $\left(\mathrm{DFa}^{\mathrm{Cl}}-\right)$ favoring $\mathrm{Cl}^{-}$exit from the cell. In contrast, both the negative apical membrane potential $\left(V\right.$ a) and low intracellular $\mathrm{Na}^{+}$activity $(\sim 20 \mathrm{mM})$ favour $\mathrm{Na}^{+}$entry into the cell. When ASL volume is low (right panel), ENaC is inhibited, which makes the apical membrane potential more negative and generates a driving force for $\mathrm{Cl}^{-}$secretion. Information regarding ASL volume is postulated to be "encoded" within the ASL.

regulatory activities emerged with the availability of the CFTR and the ENaC genes. Thus, in a variety of heterologous systems, it has been possible to show that CFTR functions as a regulator of $\mathrm{ENaC}$ [63-85]. However, it has not yet been been elucidated how the molecular interaction between CFTR and $\mathrm{ENaC}$ may occur. Theories ranging from CFTR controlling the $\mathrm{Cl}^{-}$concentration in the local membrane domain containing $\mathrm{ENaC}$ [66] to ones that involve a series of protein-protein interactions and positioning of various regulator molecules, e.g. kinases, have been proposed. Thus, this remains an important and unresolved area of research.

What has recently become more clear is the importance of both the accelerated $\mathrm{Na}^{+}$absorption and the failure to initiate
$\mathrm{Cl}^{-}$secretion to the abnormal ASL volume homeostasis in $\mathrm{CF}$. As shown schematically in figure 4b, abnormalities in both processes ultimately lead to depletion of the PCL layer and formation of thickened ("concentrated") mucus plaques and plugs adherent to CF airway surfaces. For example, studies of the well-differentiated cell culture system interfaced to the confocal microscope have provided direct evidence that $\mathrm{CF}$ airway epithelia excessively absorb ASL, deplete the PCL and lose ciliary-dependent mucus transport [47] (fig. 4). These studies have been buttressed by recent in vivo studies in $\mathrm{CF}$ mice that directly demonstrated depletion of the ASL volume (but not a difference in the ion composition) that was associated with a spontaneous airways inflammatory (goblet 
a)
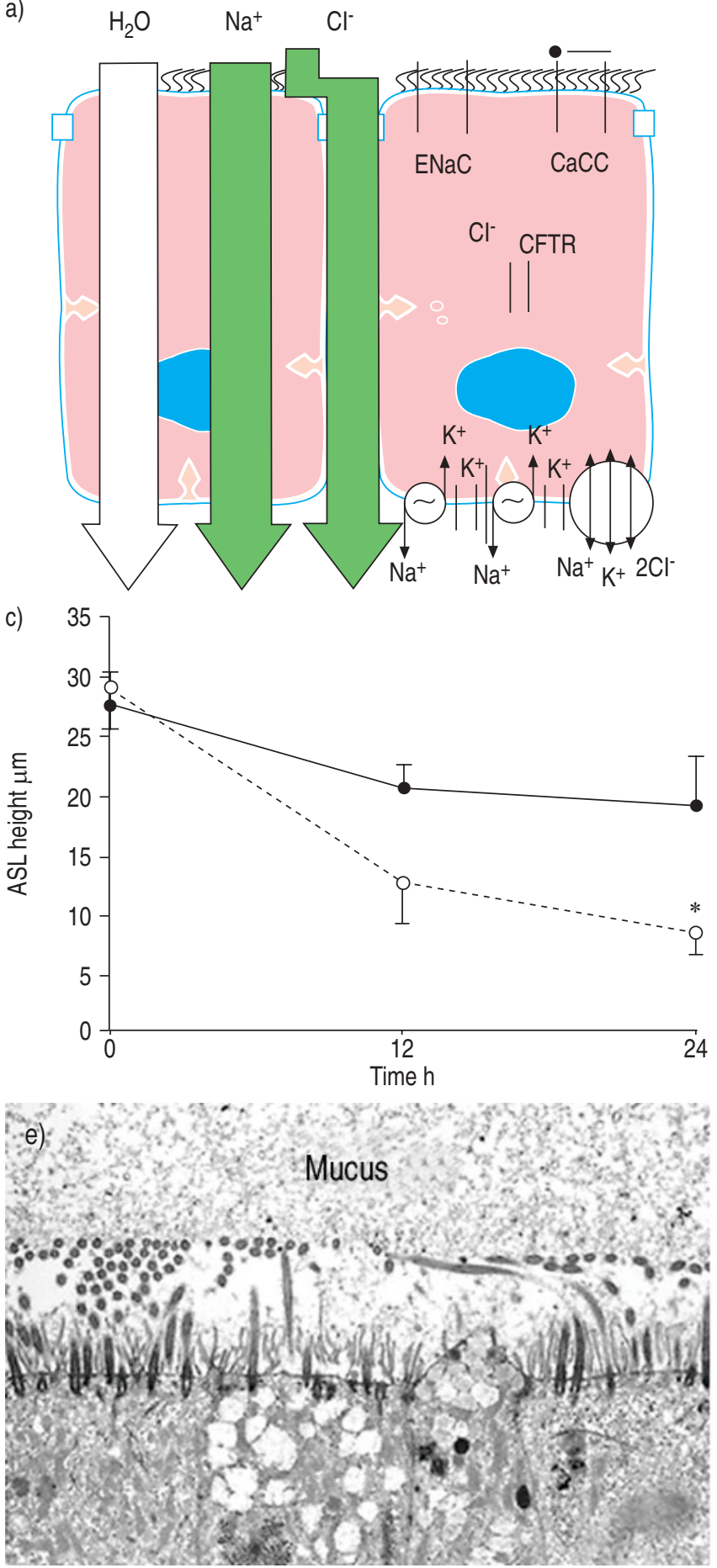

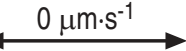

Mucus plaque
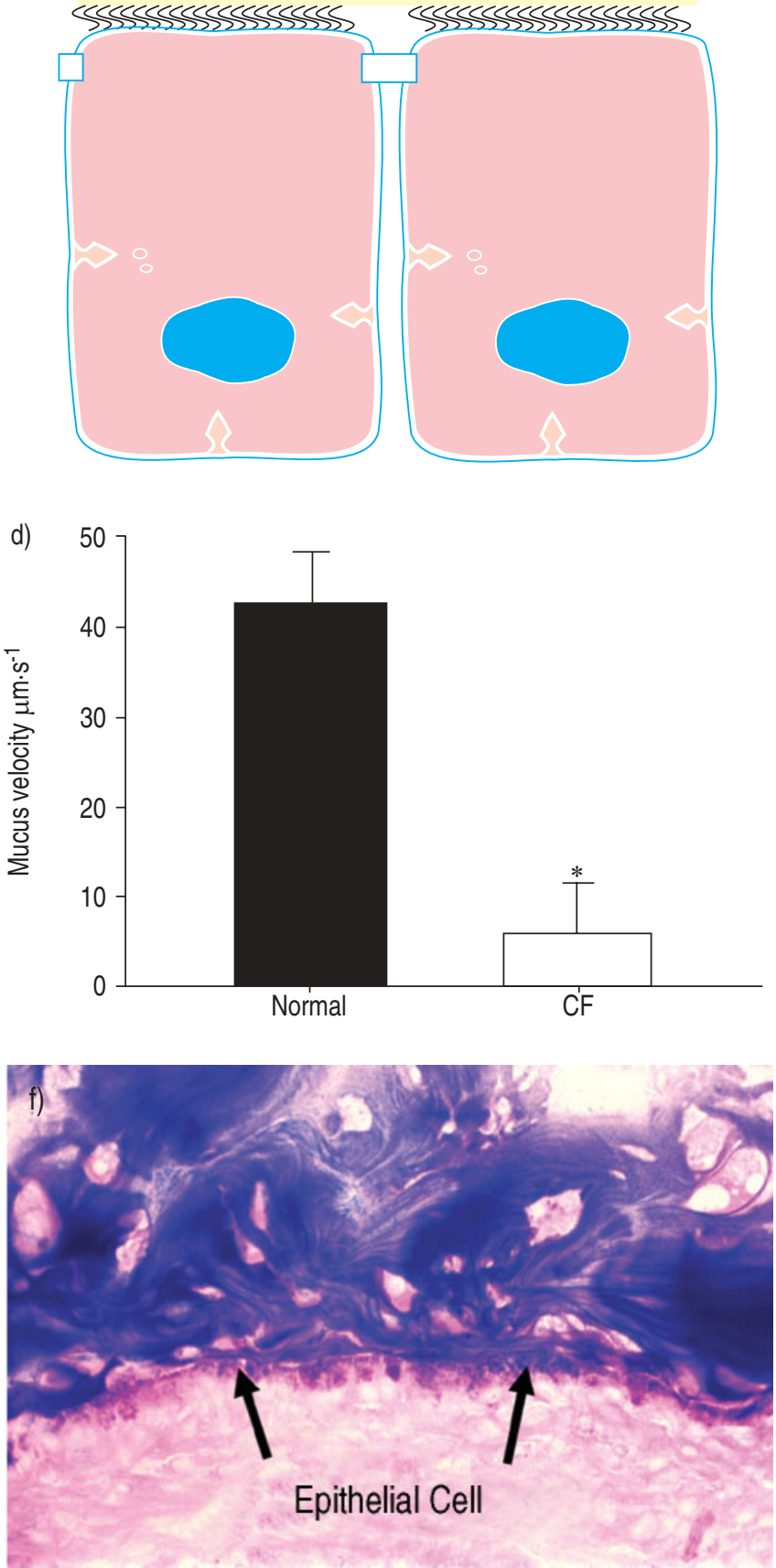

Fig. 4. - Links between abnormal epithelial ion transport and mucus stasis in cystic fibrosis (CF) airways. a) Schema showing routes for raised $\mathrm{Na}^{+}, \mathrm{Cl}^{-}$, and $\mathrm{H}_{2} \mathrm{O}$ absorption and cellular mechanisms for raised $\mathrm{Na}^{+}$transport. The absence of cystic fibrosis transmembrane regulator (CFTR) from the apical membrane both limits $\mathrm{Cl}^{-}$secretory capacity and releases the epithelial $\mathrm{Na}^{+}$channel (ENaC) from tonic inhibition. $\mathrm{CaCC}$ : $\mathrm{Ca}^{2+}$-activated "alternative" $\mathrm{Cl}^{-}$channel. b) Schema depicting the absence of periciliary liquid (PCL) layers with formation of adherent mucus plaque on CF airway epithelial cells. c) Volume absorption as measured by airway surface liquid (ASL) height with confocal microscopy. CF airway epithelia $(\bigcirc)$ absorb ASL more rapidly than normal airway epithelia $(\bullet)$. d) Effects of excessive volume absorption on rotational mucus transport $24 \mathrm{~h}$ after ASL challenge. Normal cells maintain mucus transport, whereas on CF cells mucus transport is abolished. e) Low power electron micrograph of osmium-perfluorocarbon-fixed CF culture showing PCL depletion with "bent-over" cilia and thickened mucus adhering to the glycocalyx coating ciliary shafts. f) Light micrograph of freshly excised CF airway stained with alcian blue/period acid-Schiff for mucins. Arrows point to cell surface. Area above arrows is thickened mucus that is adherent to cell surface. Adapted from [47].

cell hyperplasia) phenotype [32] and histological studies of freshly excised CF airways (fig. 4f). Thus, it appears that it is the combination of accelerated $\mathrm{Na}^{+}$transport and the failure to initiate cAMP-dependent $\mathrm{Cl}^{-}$secretion that leads to depletion of the PCL and failure of mechanical mucus clearance in $\mathrm{CF}$. 


\section{The sequence of disease that follows periciliary liquid depletion in cystic fibrosis}

\section{Mucus stasis}

The depletion of PCL prevents the cilia from extending normally (fig. 5), abolishing the efficiency of ciliary-dependent mucus clearance. A reduction in ciliary-dependent clearance may also result from the concentration (thickening) of the mucus layer, which renders its viscoelastic properties less favourable for transport. However, perhaps more problematic is the fact that PCL depletion allows the mucus layer to come into contact with the cell surface glycocalyx. It seems highly likely, but not yet proven, that adhesive interactions occur between the mucus layer and the cell surface glycocalyx that effectively "glue" the mucus layer to airway surfaces [47]. The adhesive interactions between these two layers may be further strengthened by the low $\mathrm{pH}$ that appears to characterise $\mathrm{CF}$ airway epithelial ASL [86]. It remains to be elucidated what the strength of these interactions may be, whether the interactions are dominated by carbohydratecarbohydrate interactions or protein-protein interactions, and a)

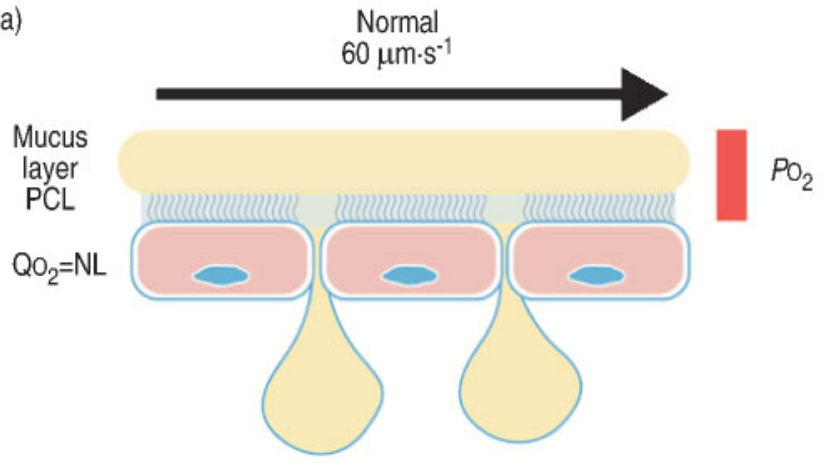

c)

e)
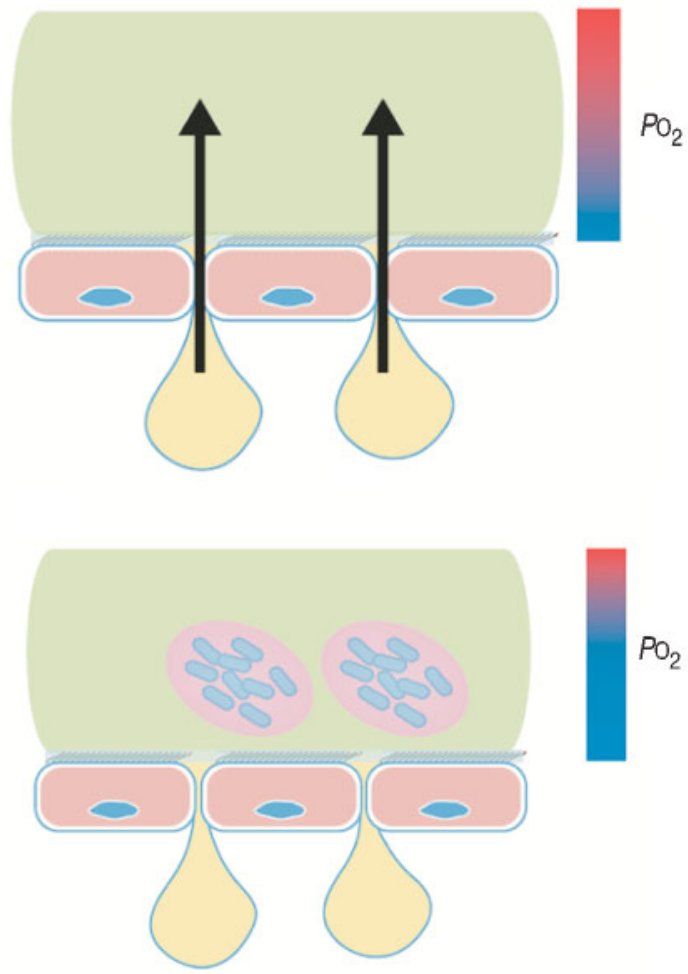

b)
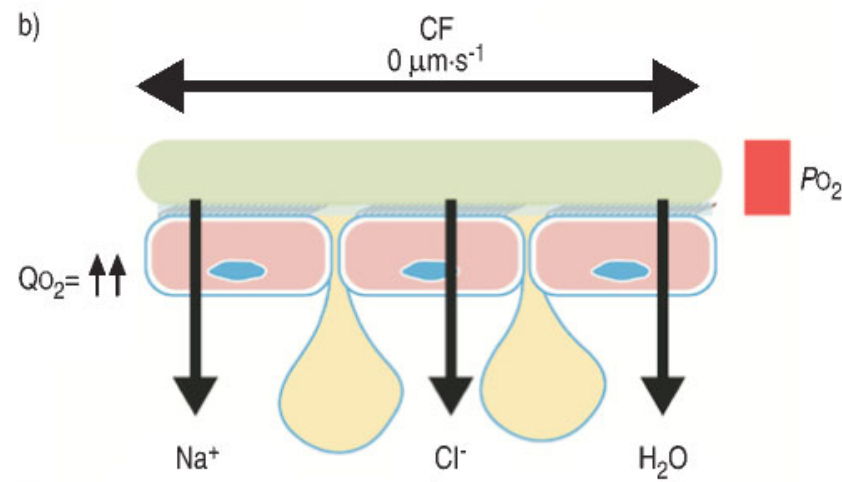

d)

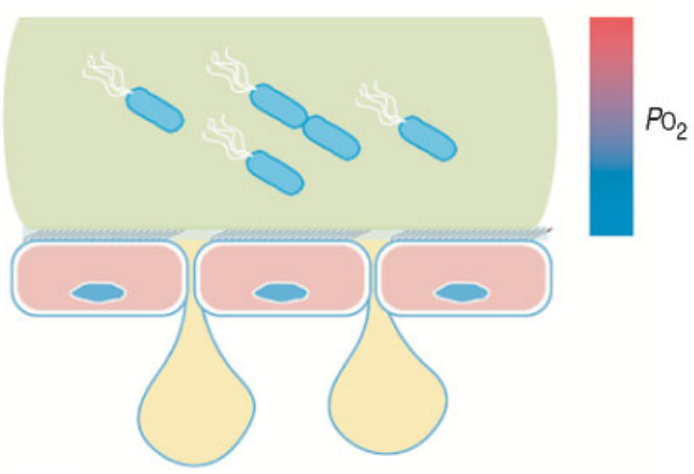

f)

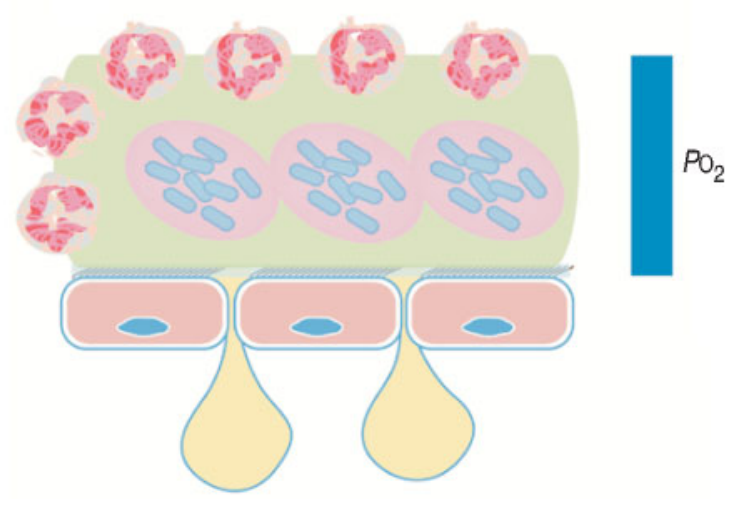

Fig. 5.-Schematic model of the pathogenic events hypothesised to lead to chronic Pseudomonas aeruginosa infection in airways of cystic fibrosis (CF) patients. a) On normal airway epithelia, a thin mucus layer resides atop the periciliary liquid (PCL) layer. The presence of the low-viscosity PCL layers facilitates efficient mucociliary clearance (denoted by vector). A normal rate of epithelial $\mathrm{O}_{2}$ consumption ( $\left(\mathrm{QO}_{2}\right.$; left) produces no $\mathrm{O}_{2}$ gradients $\left(\mathrm{PO}_{2}\right)$ within this thin airway surface liquid (ASL; denoted by light-stippled bar). b-f) CF airway epithelia. b) Excessive CF volume depletion (denoted by vertical arrows) removes the PCL layers, mucus adheres to epithelial surfaces, and mucus transport slows/stops (bidirectional vector). The raised $\mathrm{O}_{2}$ consumption (left) associated with accelerated $\mathrm{CF}$ ion transport does not generate gradients in thin films of ASL. c) Persistent mucus hypersecretion (denoted as mucus secretory gland/goblet cell elements) with time produces luminal mucus masses/plugs. The raised $\mathrm{CF}$ epithelial $\mathrm{QO}_{2}$ generates steep hypoxic gradients (light to dark stippling in bar) in thickened mucus masses. d) P. aeruginosa bacteria deposited on mucus surfaces penetrate by virtue of their flagellar activity into hypoxic zones within the mucus masses. e) $P$. aeruginosa adapts to hypoxic niches within mucus masses with increased alginate formation and the creation of macrocolonies. f) Macrocolonies resist secondary defences, including neutrophils, setting the stage for chronic infection. The presence of increased macrocolony density and, to a lesser extent, neutrophils, render the now mucopurulent mass hypoxic (dark stippled bar). Adapted from [48]. 
most importantly, how to "unglue" the mucus layer from airway surfaces. However, the functional consequence of this adhesive interaction is easily predicted, i.e. a greatly reduced efficiency of cough clearance [87]. Thus, it has been speculated that the critically important effects of PCL depletion in CF reflect the fact that both ciliary-dependent and cough clearance are abolished [47].

It should be noted that critical measurements of mucociliary clearance and cough clearance have not been made in $\mathrm{CF}$ patients, especially $\mathrm{CF}$ patients prior to infection. In part, this absence of data reflects the inability to expose control (normal) children to the radioisotopes typically used to make these measurements. Perhaps the most instructive studies available are those reported by REGNIS et al. [88] that showed reduced mucociliary clearance in $\mathrm{CF}$ patients with normal lung function compared with age-matched normal subjects.

\section{Formation of mucus plaques and mucus hypoxia}

Despite the failure to transport mucus from airway surfaces, it appears that mucin secretion persists from goblet cells and glands (fig. 5c). The continued secretion of mucins into an immobilised mucus layer will eventually lead to the formation of thick mucus plaques and plugs on airway surfaces. As these plaques approach heights of $\geqslant 100 \mu \mathrm{m}$, there appears to be a relative depletion of $\mathrm{O}_{2}$ in areas of these plaques near the $\mathrm{CF}$ cell surface [48]. The generation of mucus hypoxia reflects a combination of both the thickened plaques, providing for an increased diffusion path for $\mathrm{O}_{2}$, and accelerated epithelial $\mathrm{O}_{2}$ consumption that appears to be a unique feature of $\mathrm{CF}$ airway epithelia to fuel (via $\mathrm{O}_{2}$-consuming mitochondrial production of adenosine triphosphate (ATP)) accelerated $\mathrm{Na}^{+}$ transport.

\section{Infection of thickened hypoxic mucus plaques}

As reviewed elsewhere, when the mucus layer is being transported normally, there is turbulence within the layer that allows for efficient trapping of particulate material deposited within the mucus layer during clearance from the lung $[29,48]$. This turbulence within the mucus layer appears to cease when mucus (horizontal) transport is abolished [47]. However, recent studies have suggested that motile bacteria, including environmental strains of Pseudomonas, can penetrate into thickened mucus plaques and migrate into the hypoxic mucus zones that are just above the epithelial cell layer [48] (fig. 5d). Further, these studies demonstrated that Pseudomonas, when exposed to hypoxia, will grow in a nitrate-dependent fashion (ASL nitrate $=20 \mu \mathrm{M}$ ), with growth rates somewhat slower than under normoxic conditions (fig. 5e). However, this environment appears to be stressful to Pseudomonas, since an early phenotypic response to growth in hypoxic ASL is the formation of alginate. It is speculated that increased alginate formation reflects the conversion of planktonic Pseudomonas growth to biofilm growth under anaerobic conditions. Thus, mucus hypoxia may, in part, select for organisms that can adapt to this environment, e.g. Pseudomonas aeruginosa, and exert pressures on bacteria that promote biofilm formation.

\section{Establishment of chronic infection}

With slow proliferation of bacterial microorganisms and macrocolony/biofilm formation, the stage for persistent infection of adherent mucus is set. The growth of biofilms in thickened mucus plaques affords potential niche advantages to the bacteria (fig. 4f). It may be difficult for migratory neutrophils to penetrate into the thickened mucus plaques to engulf Pseudomonads, and the diffusion of antimicrobial activities into the thickened mucus plaques may be limited. This evasion of secondary defence mechanisms, coupled with the competitive advantages for bacteria in the biofilm form of growth, lead to the scenario that the infection of adherent mucus becomes persistent. An important prediction of these studies was that bacterial growth in densities sufficient to generate biofilms would deplete the mucus plaques of virtually all $\mathrm{O}_{2}$, rendering the infected material on airway surfaces anaerobic. This prediction was confirmed by direct in vivo measurements in CF airways [48].

The likelihood that $\mathrm{CF}$ airway infections reflect an anaerobic mucus/mucopurulent surface infection has broad implications for the therapy of $\mathrm{CF}$ infectious lung disease. For example, it has been recently shown that the sensitivity of many antibiotics is very different when bacteria are grown under aerobic versus anaerobic conditions. Perhaps the most relevant to CF have been the data of DE KIEVIT et al. [89] who showed that the sensitivity of Pseudomonas to macrolides shifted one to two logs to the left under anaerobic compared with aerobic conditions. Conversely, other commonly used antibiotics are less effective under anaerobic versus aerobic conditions. It appears that future studies should mimic the anaerobic conditions of CF airways to identify new antibiotics for therapy of persistent lung infections and inhospital testing for in vitro sensitivities should include anaerobic conditions.

\section{Are there compensations for accelerated airway surface liquid volume absorption/periciliary liquid depletion?}

It is clear that $\mathrm{CF}$ infants are born with relatively normal lungs [90], and that it takes many months to years for chronic infections to become a feature of the $\mathrm{CF}$ airways. If persistent excessive volume absorption were to generate mucus plaques from birth, CF lung disease may be expected to have a more rapid onset. In parallel, the inability to predict the severity of lung disease based on genotype suggests that there are other compensatory or modifier activities in the lung.

At present, as reviewed above, there is a search for modifier genes. With respect to potential compensatory mechanisms, it is possible that nucleotide (ATP) release secondary to persistent cough may provide sufficient ATP concentrations on airway surfaces to modify electrolyte transport and ciliary beat and thus maintain some mucus transport [91]. Alternatively, it is possible that as mucus plaques build up on airway surfaces, the increased diffusion paths for $\mathrm{O}_{2}$ restrict $\mathrm{O}_{2}$ availability to airway epithelial cells, i.e. make them hypoxic, and hence slows electrolyte transport. This scenario may be unlikely due to the large capillary circulation under the airway epithelial cells. Finally, once early infection starts, it is attractive to speculate that cytokines may modify electrolyte transport rates. For example, it is has been shown recently that inteleukin- $1 \beta$ slows the rate of $\mathrm{Na}^{+}$absorption in normal tissues, initiates $\mathrm{Cl}^{-}$and ASL secretion, alkalinises ASL to neutralise potential acidic inflammatory products on airway surfaces, and promotes secretion of rather lesser amounts of mucin, in what appears to be an integrated response to "flush" toxins off airway surfaces [92]. It has not yet been reported whether CF cells respond similarly to cytokines, but mechanisms to modify accelerated $\mathrm{Na}^{+}$transport may prove to be buffers to the rapid onset of diffuse, persistent infectious CF lung disease. 


\section{Novel therapeutic approaches}

Currently, there are a large numbers of new drugs being tested for efficacy in CF. Many of these efforts are focused on the anti-infective and the anti-inflammatory classes of drugs. In this review, the focus will be on drugs and strategies to treat the primary volume depletion defect in $\mathrm{CF}$, and the clinical ramifications of such therapies will be explored.

\section{Therapies directed at volume restoration}

As ASL is isoosmotic/isotonic, volume depletion reflects the removal of osmotically active salt and secondarily, water from airway surfaces. The recognition that a volume deficit is important in $\mathrm{CF}$ pathogenesis has led to strategies to restore osmotically active agents to airway surfaces as a simple, direct approach for adding liquid to $\mathrm{CF}$ airway surfaces. The most studied agent of this class has been inhaled hypertonic saline. The concept is that the inhaled hypertonic/hyperosmolar salt will draw water to the airway surface, enhancing the capacity of aerosol solutions deposited on the airway surface to liquefy secretions on CF airway surfaces. Several acute studies of hypertonic saline tested with a surrogate marker of efficacy for $\mathrm{CF}$, i.e. mucus clearance, have shown acute acceleration of mucus clearance [93, 94]. However, a feature of these in vivo studies has been the very short duration of action of hypertonic saline on mucus clearance. This feature has been mimicked in in vitro studies in which hypertonic saline was added to the surfaces of well-differentiated cultures interfaced to a confocal microscope to measure ASL height, ion composition and PD responses to such manoeuvres [32]. These in vitro studies revealed that the mechanism for the short duration of action reflected an upregulation of airway epithelial ion transport mechanisms to rapidly clear added $\mathrm{NaCl}$ (and $\mathrm{H}_{2} \mathrm{O}$ ) from airway surfaces. Thus, these studies would predict that long-term chronic therapeutic studies of hypertonic saline will have difficulty in demonstrating efficacy because of the short duration of active therapy. Preliminary long-term studies bear this prediction out [95], although most studies have small numbers and the largest, an Australian study, has yet to be completed.

An alternative approach is to deliver to airway surfaces osmolytes that are not actively transported and poorly absorbed. The nonelectrolyte mannitol has been one such agent tried previously. In vitro studies have demonstrated that mannitol (or, as an alternative, raffinose) added to $\mathrm{CF}$ airway surfaces can restore ASL volume for many hours, and by dilution of ASL Na${ }^{+}$concentrations, slow $\mathrm{Na}^{+}$transport [94]. However, acute in vivo studies monitoring mucus clearance again reveal a very short duration of action $(20 \mathrm{~min})$ for inhaled mannitol [96]. It is not yet clear whether the short duration of action in vivo reflects the relative inefficiency of delivering the large mass of mannitol required to produce an effective osmotic load on airway surfaces, or other factors. Based on in vitro studies, other possible poorly absorbed osmolytes that may be used in the future could be comprised of $\mathrm{K}^{+}$ions, since they are not absorbed via $\mathrm{ENaC}$ channels, and poorly absorbed anions, e.g. gluconate [32]. Recent data suggest that $\mathrm{HCO}_{3}{ }^{-}$is poorly absorbed through the paracellular path in $\mathrm{CF}$, and this feature, combined with the possible acidification of CF ASL, could make this anion an attractive component of an inhaled osmolyte therapy [86].

An alternative approach is to rebalance the abnormal ion transport properties of $\mathrm{CF}$ airway epithelia. Compounds that appear to possess actions that inhibit excessive $\mathrm{Na}^{+}$transport and trigger $\mathrm{Cl}^{-}$secretion are the triphosphate nucleotide molecules (e.g. ATP or uridine triphosphate). Triphosphate nucleotides interact with apical membrane $\mathrm{P} 2 \mathrm{Y}_{2}$ nucleotide receptors that are coupled to activation of phospholipase C- $\beta$. A variety of studies in cultured cells, and, most compellingly, freshly excised human airway epithelia have demonstrated that luminally applied UTP both inhibits ENaC-mediated $\mathrm{Na}^{+}$absorption and triggers $\mathrm{Ca}^{2+}$-activated $\mathrm{Cl}^{-}$secretion in $\mathrm{CF}$ as well as normal airway epithelia [97-102]. Further, studies of ASL volume responses to UTP with confocal microscopy have revealed that the net effect of inhibition of $\mathrm{Na}^{+}$transport and activation of $\mathrm{Cl}^{-}$transport is that volume is secreted onto the surface of $\mathrm{CF}$ airway epithelia and, as predicted from previous electrophysiological studies, the volume secretory response to UTP is greater in CF than normal cultures [32]. Finally, acute administration of UTP will restore the PCL and rotational mucus transport in welldifferentiated cultures of CF airway epithelia [32].

These data have set the stage for development of purinoceptor agonists for CF therapy. Early candidates, e.g. UTP, were shown to be poor drug candidates due to rapid hydrolysis ( 45 s half-life) on airway surfaces [32]. These observations led to the search for stabilised nucleotide analogues that were active at the luminal $\mathrm{P} 2 \mathrm{Y}_{2}$ receptor. INS37217 is a candidate nucleotide analogue that is both active at $\mathrm{P} 2 \mathrm{Y}_{2}-\mathrm{R}$ and resistant to hydrolysis by airway cell surface nucleotidases and hydrolysis by nucleotidases contained in mucus of $\mathrm{CF}$ patients [103]. Initial Phase I safety studies of INS37217 in $\mathrm{CF}$ adults have been completed and INS37217 was found to be safe. currently, INS37217's efficacy in improving lung function and increasing muscle clearance, as assessed by CT scanning, is being tested in phase-II studies through the Cystic Fibrosis Foundation Therapeutic Development Network.

A complementary approach is to directly inhibit the ENaC that mediates volume hyperabsorption. This concept originated from studies performed many years ago that demonstrated that the raised nasal PD in CF airway epithelia was inhibited by topically applied amiloride [53]. Subsequent studies employing surrogate markers, e.g. mucus clearance, showed that aerosolised amiloride was effective acutely in $\mathrm{CF}$ patients [104]. Further, inhaled amiloride appeared to preserve forced expiratory volume in one second, in a small, long-term (6month) crossover study in which most other therapies for CF were eliminated [105]. However, studies that have evaluated amiloride in the context of usual therapies failed to detect clinical benefit [106].

Studies of the pharmacodynamic properties of amiloride revealed that the half-life of amiloride on airway surfaces was $\sim 20-30$ min, suggesting its duration of action was insufficient to treat CF lung disease chronically even when administered four times per day [32, 107]. Since amiloride is of relatively low potency and insoluble in solution, its duration of action could not be extended simply by increasing the inhaled dose. Recent studies in patients with congenital loss of function of airway $\mathrm{ENaC}$, i.e. pseudohypoaldosteronism (PHA), showed that these patients had increased volumes of liquid on airway surfaces and compensated for this defect in $\mathrm{Na}^{+}$-dependent liquid absorption by greatly accelerating mucus (ASL) clearance [108]. These observations suggest that high potency, long-acting $\mathrm{Na}^{+}$channel blockers, mimicking the completeness of PHA ENaC block, may have sufficient activity to restore the ASL volume deficit and restore mucus clearance in $\mathrm{CF}$.

\section{Clinical lessons from the use of volume-restoring agents}

From studies of hypertonic saline and first- and secondgeneration purinoceptor agonists, it appears that several themes are emerging with respect to clinical use of agents that 
add volume to airway surfaces. First, as shown in figure 6a, adding volume to dehydrated mucus plugs is predicted to make them "swell". As these plugs move from distal smaller airways to more proximal airways, the increased size of the plug may lead to transient obstruction of larger airways, with periods of transient volume/perfusion mismatch and hypoxaemia. It appears from studies of both purinoceptor agonists and hypertonic saline that this phenomenon does occur, but is transient, i.e. $\leqslant 30 \min [109,110]$.

Secondly, mucus that is mobilised has to be coughed from the lung to be cleared. Thus, use of hypertonic saline and/or pharmacological agents of the volume-restoring class may be associated with increases in cough post-therapy in keeping with their expectorant action. Presumably, therefore, a "productive" cough following inhalation of drug or osmolytes is an index of efficacy rather than an adverse event.

Thirdly, the CF lung in young adults may contain up to $150 \mathrm{~mL}$ of thickened, concentrated mucopurulent material (fig. 6b). For example, if the percentage solids ("concentration") of normal mucus is $1.5 \%$, and $\mathrm{CF}$ mucus $15 \%$, then to "thin" CF mucus to a normal level so that it can be cleared requires that $\sim 1,350 \mathrm{~mL}$ of liquid be added to airway surfaces. Since the volume of the conducting airways in a young adult is $\sim 300 \mathrm{~mL}$, if this thinning process were performed acutely, the patient would, in effect "drown". Thus, because it has taken CF patients many months or years to accumulate this volume of thickened mucus, it would appear sensible to take a "low-dose medication/go slow" approach to removing these inspissated materials. This latter admonition may have effects on clinical trials, i.e. the ability to capture the efficacy

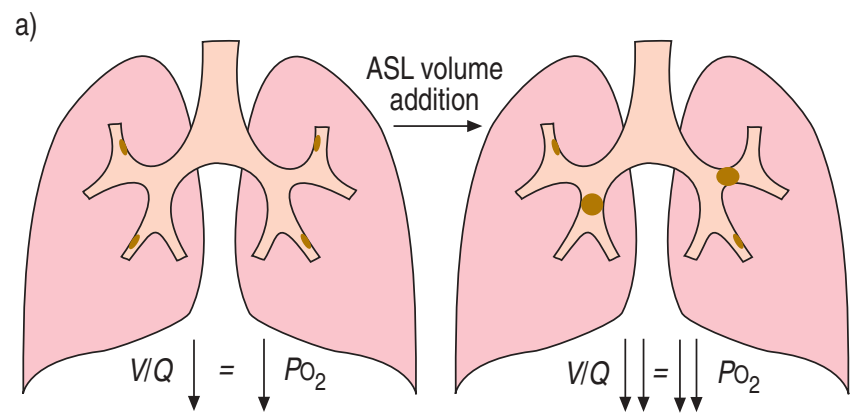

b)

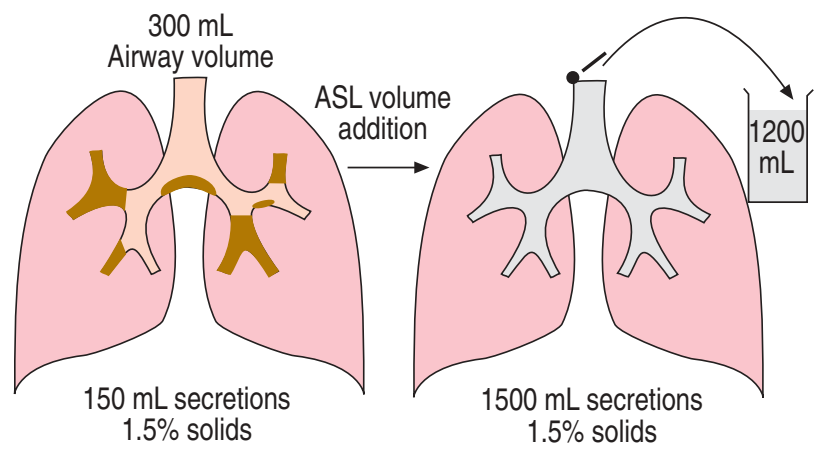

Fig. 6.-Potential clinically relevant outcomes of "volume addition" therapies. a) Scenario by which dehydrated mucus plugs could cause transient worsening of hypoxia as they are moved from distal to proximal airway after rehydration and expansion. b) Scenario depicting "volume debt" burden of cystic fibrosis airways with markedly dehydrated $(15 \%$ solids) mucopurulent material occupying $\sim 50 \%$ of the airway luminal volume. Rapid normalisation of mucus hydration $(\sim 1.5 \%$ solids $)$ would lead to filling of airway luminal volume (drowning), plus a large volume $(1200 \mathrm{~mL})$ of expectorated material. ASL: airway surface liquid; VIQ: volume/perfusion; $P_{\mathrm{O}_{2}}$ : oxygen tension. of these compounds versus potential adverse events due to cough and transient hypoxaemia, would appear better in trials of low doses of compounds for prolonged periods.

Finally, it is not clear that initiation of volume-restoring therapies by aerosol after CF lung disease is established, with poor airflow, and hence, limited delivery to mucus-obstructed regions will effectively "chip away" obstructing plugs. Several solutions to this problem are apparent. The simplest is to start therapy early in the life of CF patients before obstruction occurs. For patients with substantial obstruction, delivery of drugs parenterally is rational, but no volume-restoring drugs are available for use by this route. A final thought, borrowed from cancer trials, is that perhaps therapy with volumerestoring agents should include both "induction" and "maintenance" phases. Thus, it may be reasonable to consider "debulking" CF patients of retained mucus with intensive inhalational therapy with multiple complementary agents, e.g., volume restoring agents, mucolytics, and deoxyribonuclease, and vigorous physical therapy. This phase would be followed by maintenance therapy with inhaled ion transport modulators.

\section{Conclusion}

The processes that initiate and perpetuate CF lung disease have perhaps become more clear. If volume depletion on $\mathrm{CF}$ airway surfaces, particularly the PCL, is the initiating lesion, then all efforts should be made to redress this defect. In health, the PCL may equal $\sim 3.5 \mathrm{~mL}$, suggesting that restoring this volume early in life should not be difficult. However, the problem is to achieve this result chronically, i.e. $24 \mathrm{~h} \cdot \mathrm{day}^{-1}$. The half-life of small molecular weight osmolytes $(\sim 500)$ and hydrophilic drugs may be only $\sim 1.5 \mathrm{~h}$ on airway surfaces, likely a reflection of the relatively permeable paracellular path that characterises airway surfaces. Thus, for osmolytes to be effective, they may have to be given continually. For drugs to be effective, they will have to be given safely in concentrations far in excess of their half-maximal activity level and/or have extended pharmacodynamic effects.

For treatment of the infectious components of mucus stasis, the ramifications of cystic fibrosis airway lumen anaerobiasis must be explored. These studies should focus on novel antimicrobial targets based on processes ratelimiting for bacterial adaptation to anaerobic environments and evaluate the utility of routine hospital testing of cystic fibrosis isolates for antimicrobial sensitivities under anaerobic conditions. Despite these technical obstacles, the path to novel and specific therapy for cystic fibrosis lung disease seems clear. The goal of the cystic fibrosis community is to move down this path with a broad variety of approaches as rapidly and safely as possible.

\section{References}

1. Kerem B-T, Rommens JM, Buchanan JA, et al. Identification of the cystic fibrosis gene: genetic analysis. Science 1989; 245: 1073-1080.

2. Riordan JR, Rommens JM, Kerem B-T, et al. Identification of the cystic fibrosis gene: cloning and characterization of complementary DNA. Science 1989; 245: 1066-1073.

3. Rommens JM, Iannuzzi MC, Kerem B-T, et al. Identification of the cystic fibrosis gene: chromosome walking and jumping. Science 1989; 245: 1059-1065.

4. FitzSimmons SC. CFF Patient Registry. 1997 Annual Data Report. Bethesda, Cystic Fibrosis Foundation, 1998.

5. Welsh MJ, Tsui L-C, Boat TF, Beaudet AL. Cystic fibrosis. In: Scriver CR, Beaudet AL, Sly WS et al., eds. The 
Metabolic and Molecular Bases of Inherited Disease. New York, McGraw-Hill Inc., 1995; pp. 3799-3876.

6. Tuemmler B, Kiewitz C. Cystic fibrosis: an inherited susceptibility to bacterial respiratory infections. Mol Med Today 1999; 5: 351-358.

7. Cystic Fibrosis Gene Analysis Consortium. www.genet. sickkids.on.ca/cftr/2000. Last updated September 9, 1998. Accessed July 31, 2003.

8. Cutting GR. Genotype defect: its effect on cellular function and phenotypic expression. Semin Respir Crit Care Med 1994; 15: 356-363.

9. Zielenski J, Tsui LC. Cystic fibrosis: genotypic and phenotypic variations. Annu Rev Genet 1995; 29: 777-807.

10. Kerem E, Corey M, Kerem B-S, et al. The relation between genotype and phenotype in cystic fibrosis - analysis of the most common mutation $\left(\mathrm{DF}_{508}\right)$. N Engl J Med 1990; 323: $1517-1522$.

11. Santis G, Osborne L, Knight RA, Hodson ME. Independent genetic determinants of pancreatic and pulmonary status in cystic fibrosis. Lancet 1990; 336: 1081-1084.

12. Mahadeva R, Sharples L, Ross-Russell RI, Webb AK, Bilton D, Lomas DA. Association of alpha(1)-antichymotrypsin deficiency with milder lung disease in patients with cystic fibrosis. Thorax 2001; 56: 53-58.

13. Garred P, Pressler T, Madsen HO, et al. Association of mannose-binding lectin gene heterogeneity with severity of lung disease and survival in cystic fibrosis. J Clin Invest 1999; 104: 431-437.

14. Hull J, Thomson AH. Contribution of genetic factors other than CFTR to disease severity in cystic fibrosis. Thorax 1998; 53: 1018-1021.

15. Arkwright PD, Laurie S, Super M, et al. TGF-beta(1) genotype and accelerated decline in lung function of patients with cystic fibrosis. Thorax 2000; 55: 459-462.

16. Gabolde M, Guilloud-Bataille M, Feingold J, Besmond C. Association of variant alleles of mannose binding lectin with severity of pulmonary disease in cystic fibrosis: cohort study. BMJ 1999; 319: 1167.

17. Mahadeva R, Stewart S, Bilton D, Lomas DA. Alpha-1 antitrypsin deficiency alleles and severe cystic fibrosis lung disease. Thorax 1998; 53: 1022-1024.

18. Fan JB, Chen X, Halushka MK, et al. Parallel genotyping of human SNPs using generic high-density oligonucleotide tag arrays. Genome Res 2000; 10: 853-860.

19. Lindblad-Toh K, Winchester E, Daly MJ, et al. Large-scale discovery and genotyping of single-nucleotide polymorphisms in the mouse. Nat Genet 2000; 24: 381-386.

20. Welsh MJ, Smith AE. Molecular mechanisms of CFTR chloride channel dysfunction in cystic fibrosis. Cell 1993; 73: $1251-1254$.

21. Cheng SH, Gregory RJ, Marshall J, et al. Defective intracellular transport and processing of CFTR is the molecular basis of most cystic fibrosis. Cell 1990; 63: 827-834.

22. Kartner N, Augustinas O, Jensen TJ, Naismith AL, Riordan JR. Mislocalization of DF508 CFTR in cystic fibrosis sweat gland. Nat Genet 1992; 1: 321-327.

23. Kalin N, Claabeta A, Sommer M, Puchelle E, Tummler B. DeltaF508 CFTR protein expression in tissues from patients with cystic fibrosis. J Clin Invest 1999; 103: 1379-1389.

24. Bronsveld I, Mekus F, Bijman J, et al. Chloride conductance and genetic background modulate the cystic fibrosis phenotype of Delta F508 homozygous twins and siblings. J Clin Invest 2001; 108: 1705-1715.

25. Engelhardt JF, Yankaskas JR, Ernst SA, et al. Submucosal glands are the predominant site of CFTR expression in human bronchus. Nat Genet 1992; 2: 240-247.

26. Engelhardt JF, Zepeda M, Cohn JA, Yankaskas JR, Wilson JM. Expression of the cystic fibrosis gene in adult human lung. J Clin Invest 1994; 93: 737-749.

27. Drumm ML, Wilkinson DJ, Smith LS, et al. Chloride conductance expressed by delta F508 and other mutant CFTRs in Xenopus oocytes. Science 1991; 254: 1797-1799.
28. Li C, Ramjeesingh M, Reyes E, et al. The cystic fibrosis mutation (DeltaF508) does not influence the chloride channel activity of CFTR. Nat Genet 1993; 3: 311-316.

29. Knowles MR, Boucher RC. Mucus clearance as a primary innate defense mechanism for mammalian airways ("Perspective"). J Clin Invest 2002; 109: 571-577.

30. Wanner A, Salathe M, O'Riordan TG. Mucociliary clearance in the airways. Am J Respir Crit Care Med 1996; 154: $1868-1902$.

31. Cole AM, Dewan P, Ganz T. Innate antimicrobial activity of nasal secretions. Infect Immun 1999; 67: 3267-3275.

32. Tarran R, Grubb BR, Parsons D, et al. The CF salt controversy: in vivo observations and therapeutic approaches. Mol Cell 2001; 8: 149-158.

33. Tarran R, Grubb BR, Gatzy JT, Davis CW, Boucher RC. The relative roles of passive surface forces and active ion transport in the modulation of airway surface liquid volume and composition. J Gen Physiol 2001; 118: 223-236.

34. Boucher RC. Human airway ion transport (Part 1). Am J Respir Crit Care Med 1994; 150: 271-281.

35. Joris L, Dab I, Quinton PM. Elemental composition of human airway surface liquid in healthy and diseased airways. Am Rev Respir Dis 1993; 148: 1633-1637.

36. Smith JJ, Travis SM, Greenberg EP, Welsh MJ. Cystic fibrosis airway epithelia fail to kill bacteria because of abnormal airway surface fluid. Cell 1996; 85: 229-236.

37. Goldman MJ, Anderson GM, Stolzenberg ED, Kari UP, Zasloff M, Wilson JM. Human beta-defensin-1 is a saltsensitive antibiotic that is inactivated in cystic fibrosis. Cell 1997; 88: 553-560.

38. Knowles MR, Robinson JM, Wood RE, et al. Ion composition of airway surface liquid of patients with cystic fibrosis as compared to normal and disease-control subjects. J Clin Invest 1997; 100: 2588-2595.

39. Caldwell RA, Grubb BR, Tarran R, Boucher RC, Knowles MR, Barker PM. In vivo airway surface liquid $\mathrm{Cl}^{-}$ analysis with solid-state electrodes. J Gen Physiol 2002; 119: 3-14.

40. Jayaraman S, Song Y, Vetrivel L, Shankar L, Verkman AS. Noninvasive in vivo fluorescence measurement of airwaysurface liquid depth, salt concentration, and $\mathrm{pH}$. J Clin Invest 2001; 107: 317-324.

41. Hull J, Skinner W, Robertson C, Phelan P. Elemental content of airway surface liquid from infants with cystic fibrosis. Am J Respir Crit Care Med 1998; 157: 10-14.

42. Grubb BR, Chadburn JL, Boucher RC. In vivo microdialysis for the determination of airway surface liquid ion composition. Am J Physiol 2002; 282: C1423-C1431.

43. Wine JJ. The genesis of cystic fibrosis lung disease. J Clin Invest 1999; 103: 309-312.

44. Guggino WB. Cystic fibrosis and the salt controversy. Cell 1999; 96: 607-610.

45. Boucher RC. Molecular insights into the physiology of the 'thin film' of airway surface liquid. J Physiol 1999; 516: 631638.

46. Matsui H, Randell SH, Peretti SW, Davis CW, Boucher RC. Coordinated clearance of periciliary liquid and mucus from airway surfaces. J Clin Invest 1998; 102: 1125-1131.

47. Matsui H, Grubb BR, Tarran R, et al. Evidence for periciliary liquid layer depletion, not abnormal ion composition, in the pathogenesis of cystic fibrosis airways disease. Cell 1998; 95: 1005-1015.

48. Worlitzsch D, Tarran R, Ulrich M, et al. Effects of reduced mucus oxygen concentration in airway Pseudomonas infections of cystic fibrosis patients. J Clin Invest 2002; 109: 317-325.

49. Lamblin G, Degroote S, Perini JM, et al. Human airway mucin glycosylation: a combinatory of carbohydrate determinants which vary in cystic fibrosis. BioLeXis 2000; 1: 47.

50. Canessa CM, Schild L, Buell G, et al. Amiloride-sensitive epithelial $\mathrm{Na}^{+}$channel is made of three homologous subunits. Nature 1994; 367: 463-467. 
51. Canessa CM, Horisberger J-D, Rossier BC. Epithelial sodium channel related to proteins involved in neurodegeration. Nature 1993; 361: 467-470.

52. Huang $\mathrm{P}$, Lazarowski ER, Tarran R, Milgram SL, Boucher RC, Stutts MJ. Compartmentalized autocrine signaling to cystic fibrosis transmembrane conductance regulator at the apical membrane of airway epithelial cells. Proc Natl Acad Sci USA 2001; 98: 14120-14125.

53. Knowles M, Gatzy J, Boucher R. Increased bioelectric potential difference across respiratory epithelia in cystic fibrosis. N Engl J Med 1981; 305: 1489-1495.

54. Knowles M, Gatzy J, Boucher R. Relative ion permeability of normal and cystic fibrosis nasal epithelium. $J$ Clin Invest 1983; 71: 1410-1417.

55. Boucher RC, Stutts MJ, Knowles MR, Cantley L, Gatzy JT. $\mathrm{Na}^{+}$transport in cystic fibrosis respiratory epithelia. Abnormal basal rate and response to adenylate cyclase activation. J Clin Invest 1986; 78: 1245-1252.

56. Hirsh AJ, Boucher RC. Absorption of $\mathrm{Na}^{+}$channel inhibitors by cystic fibrosis airway epithelium. Pediatr Pulmonol Suppl 2000; 20: 248.

57. Boucher RC. Human airway ion transport (Part 2). Am J Respir Crit Care Med 1994; 150: 581-593.

58. Willumsen NJ, Davis CW, Boucher RC. Cellular $\mathrm{Cl}^{-}$ transport in cultured cystic fibrosis airway epithelium. $\mathrm{Am} \mathrm{J}$ Physiol 1989; 256: C1045-C1053.

59. Willumsen NJ, Davis CW, Boucher RC. Intracellular $\mathrm{Cl}^{-}$ activity and cellular $\mathrm{Cl}^{-}$pathways in cultured human airway epithelium. Am J Physiol 1989; 256: C1033-C1044.

60. Willumsen NJ, Boucher RC. Sodium transport and intracellular sodium activity in cultured human nasal epithelium. Am J Physiol 1991; 261: C319-C331.

61. Willumsen NJ, Boucher RC. Transcellular sodium transport in cultured cystic fibrosis human nasal epithelium. Am J Physiol 1991; 261: C332-C341.

62. Chinet TC, Fullton JM, Yankaskas JR, Boucher RC, Stutts MJ. Mechanism of sodium hyperabsorption in cultured cystic fibrosis nasal epithelium: a patch clamp study. Am J Physiol 1994; 266: C1061-C1068.

63. Stutts MJ, Canessa CM, Olsen JC, et al. CFTR as a cAMPdependent regulator of sodium channels. Science 1995; 269: $847-850$.

64. Stutts MJ, Rossier BC, Boucher RC. Cystic fibrosis transmembrane conductance regulator inverts protein kinase A-mediated regulation of epithelial sodium channel single channel kinetics. J Biol Chem 1997; 272: 14037-14040.

65. Mall M, Hipper A, Greger R, Kunzelmann K. Wild type but not delta F508 CFTR inhibits $\mathrm{Na}^{+}$conductance when coexpressed in Xenopus oocytes. FEBS Lett 1996; 381: 4752.

66. Konig J, Schreiber R, Voelcker T, Mall M, Kunzelmann K. The cystic fibrosis transmembrane conductance regulator (CFTR) inhibits ENaC through an increase in the intracellular Cl- concentration. EMBO Rep 2001; 2: 1047-1051.

67. Boucherot A, Schreiber R, Kunzelmann K. Role of CFTR's PDZ1-binding domain, $\mathrm{NBF} 1$ and $\mathrm{Cl}(-)$ conductance in inhibition of epithelial $\mathrm{Na}(+)$ channels in Xenopus oocytes. Biochim Biophys Acta 2001; 1515: 64-71.

68. Kunzelmann K, Schreiber R, Boucherot A. Mechanisms of the inhibition of epithelial $\mathrm{Na}(+)$ channels by CFTR and purinergic stimulation. Kidney Int 2001; 60: 455-461.

69. Kunzelmann K. CFTR: interacting with everything? News Physiol Sci 2001; 16: 167-170.

70. Kunzelmann K, Schreiber R, Nitschke R, Mall M. Control of epithelial $\mathrm{Na}+$ conductance by the cystic fibrosis transmembrane conductance regulator. Pfluegers Arch 2000; 440: 193-201.

71. Mall M, Bleich M, Kuehr J, Brandis M, Greger R, Kunzelmann K. CFTR-mediated inhibition of epithelial $\mathrm{Na}+$ conductance in human colon is defective in cystic fibrosis. Am J Physiol 1999; 277: G709-G716.

72. Hopf A, Schreiber R, Mall M, Greger R, Kunzelmann K.
Cystic fibrosis transmembrane conductance regulator inhibits epithelial $\mathrm{Na}+$ channels carrying Liddle's syndrome mutations. J Biol Chem 1999; 274: 13894-13899.

73. Schreiber R, Hopf A, Mall M, Greger R, Kunzelmann K. The first-nucleotide binding domain of the cystic-fibrosis transmembrane conductance regulator is important for inhibition of the epithelial Na+ channel. Proc Natl Acad Sci USA 1999; 96: 5310-5315.

74. Kunzelmann K. The cystic fibrosis transmembrane conductance regulator and its function in epithelial transport. Rev Physiol Biochem Pharmacol 1999; 137: 1-70.

75. Kunzelmann K, Schreiber R. CFTR, a regulator of channels. J Membr Biol 1999; 168: 1-8.

76. Mall M, Bleich M, Greger R, Schreiber R, Kunzelmann K. The amiloride-inhibitable $\mathrm{Na}+$ conductance is reduced by the cystic fibrosis transmembrane conductance regulator in normal but not in cystic fibrosis airways. J Clin Invest 1998; 102: $15-21$.

77. Kunzelmann K, Kiser GL, Schreiber R, Riordan JR. Inhibition of epithelial $\mathrm{Na}+$ currents by intracellular domains of the cystic fibrosis transmembrane conductance regulator. FEBS Lett 1997; 400: 341-344.

78. Greger R, Mall M, Bleich M, et al. Regulation of epithelial ion channels by the cystic fibrosis transmembrane conductance regulator. J Mol Med 1996; 74: 527-534.

79. Ji HL, Chalfant ML, Jovov B, et al. The cytosolic termini of the beta- and gamma-ENaC subunits are involved in the functional interactions between cystic fibrosis transmembrane conductance regulator and epithelial sodium channel. J Biol Chem 2000; 275: 27947-27956.

80. Ismailov II, Awayda MS, Jovov B, et al. Regulation of epithelial sodium channels by the cystic fibrosis transmembrane conductance regulator. J Biol Chem 1996; 271: 4725-4732.

81. Ismailov II, Berdiev BK, Shlyonsky VG, et al. Role of actin in regulation of epithelial sodium channels by CFTR. Am J Physiol 1997; 272: C1077-C1086.

82. Schwiebert EM, Benos DJ, Egan ME, Stutts MJ, Guggino WB. CFTR is a conductance regulator as well as a chloride channel. Physiol Rev 1999; 79: Suppl. 1, S145-S166.

83. Ji HL, Jovov B, Fu J, et al. Upregulation of acid-gated $\mathrm{Na}(+)$ channels (ASICs) by cystic fibrosis transmembrane conductance regulator co-expression in Xenopus oocytes. J Biol Chem 2002; 277: 8395-8405.

84. Jiang Q, Li J, Dubroff R, et al. Epithelial sodium channels regulate cystic fibrosis transmembrane conductance regulator chloride channels in Xenopus oocytes. J Biol Chem 2000; 275: $13266-13274$.

85. Suaud L, Li J, Jiang Q, Rubenstein RC, Kleyman TR. Genistein restores functional interactions between Delta F508-CFTR and ENaC in Xenopus oocytes. $J$ Biol Chem 2002; 277: 8928-8933.

86. Coakley RD, Paradiso AM, Grubb BR, Gatzy JT, Chadburn JL, Boucher RC. Abnormal airway surface liquid $\mathrm{pH}\left(\mathrm{pH}_{\mathrm{ASL}}\right)$ regulation in cultured $\mathrm{CF}$ bronchial epithelium. Pediatr Pulmonol Suppl 2000; 14: 194

87. King M, Zahm JM, Pierrot D, Vaquez-Girod S, Puchelle E. The role of mucus gel viscosity, spinnability, and adhesive properties in clearance by simulated cough. Biorheology 1989; 26: 737-745.

88. Regnis JA, Robinson M, Bailey DL, et al. Mucociliary clearance in patients with cystic fibrosis and in normal subjects. Am J Respir Crit Care Med 1994; 150: 66-71.

89. de Kievit TR, Parkins MD, Gillis RJ, et al. Multidrug efflux pumps: expression patterns and contribution to antibiotic resistance in Pseudomonas aeruginosa biofilms. Antimicrob Agents Chemother 2001; 45: 1761-1770.

90. Tomashefski JF Jr, Dahms BB, Abramowsky CR. The pathology of cystic fibrosis. In: Davis PB, ed. Cystic Fibrosis. New York, Marcel Dekker Inc., 1993; pp. 435-489.

91. Lazarowski ER, Homolya L, Boucher RC, Harden TK. Direct demonstration of mechanically induced release of 
cellular UTP and its implication for uridine nucleotide receptor activation. $J$ Biol Chem 1997; 272: 24348-24354.

92. Gray T, Loftin C, Tiano H, Langenbach R, Bonner J, Nettesheim P. Cylocooxygenase-2 generated PGE2 mediates cytokine-induced Muc5ac mucin hyper-secretion by human airway epithelium. Am J Respir Crit Care Med 2002; 165: A70.

93. Robinson M, Regnis JA, Bailey DL, King M, Bautovich GJ, Bye PT. Effect of hypertonic saline, amiloride, and cough on mucociliary clearance in patients with cystic fibrosis. $\mathrm{Am} \mathrm{J}$ Respir Crit Care Med 1996; 153: 1503-1509.

94. Robinson M, Hemming AL, Regnis JA, et al. Effect of increasing doses of hypertonic saline on mucociliary clearance in patients with cystic fibrosis. Thorax 1997; 52: 900-903.

95. Suri R, Metcalfe C, Lees B, et al. Comparison of hypertonic saline and alternate-day or daily recombinant human deoxyribonuclease in children with cystic fibrosis: a randomised trial. Lancet 2001; 358: 1316-1321.

96. Robinson M, Daviskas E, Eberl S, et al. The effect of inhaled mannitol on bronchial mucus clearance in cystic fibrosis patients: a pilot study. Eur Respir J 1999; 14: 678-685.

97. Mall M, Wissner A, Gonska T, et al. Inhibition of amiloridesensitive epithelial $\mathrm{Na}(+)$ absorption by extracellular nucleotides in human normal and cystic fibrosis airways. Am J Respir Cell Mol Biol 2000; 23: 755-761.

98. Devor DC, Bridges RJ, Pilewski JM. Pharmacological modulation of ion transport across wild-type and deltaF508 CFTR-expressing human bronchial epithelia. Am J Physiol 2000; 279: C461-C479.

99. Devor DC, Pilewski JM. UTP inhibits $\mathrm{Na}^{+}$absorption in normal and CF human airway epithelia. Pediatr Pulmonol Suppl 1997; 14: 242.

100. Devor DC, Pilewski JM. UTP inhibits $\mathrm{Na}^{+}$absorption in wild-type and DeltaF508 CFTR-expressing human bronchial epithelia. Am J Physiol 1999; 276: C827-C837.

101. Clarke LL, Boucher RC. Chloride secretory response to extracellular ATP in normal and cystic fibrosis nasal epithelia. Am J Physiol 1992; 263: C348-C356.
102. Knowles MR, Clarke LL, Boucher RC. Activation by extracellular nucleotides of chloride secretion in the airway epithelia of patients with cystic fibrosis. N Engl J Med 1991; 325: 533-538.

103. Yerxa B, Sabater JR, Davis CW, et al. Pharmacology of INS37217, a next generation P2Y2 receptor agonist for the treatment of cystic fibrosis. J Pharmacol Exp Ther 2002; 302: 871-880.

104. Kohler D, App E, Schmitz-Schumann M, Wuertemberger G, Matthys H. Inhalation of amiloride improves the mucociliary and the cough clearance in patients with cystic fibroses. Eur J Respir Dis 1986; 69: Suppl. 146, 319-326.

105. Knowles MR, Church NL, Waltner WE, et al. A pilot study of aerosolized amiloride for the treatment of lung disease in cystic fibrosis. $N$ Engl J Med 1990; 322: 11891194.

106. Graham A, Hasani A, Alton EWFW, et al. No added benefit from nebulized amiloride in patients with cystic fibrosis. Eur Respir J 1993; 6: 1243-1248.

107. Knowles MR, Church NL, Waltner WE, Gatzy JT, Boucher RC. Amiloride in cystic fibrosis: safety, pharmacokinetics, and efficacy in the treatment of pulmonary disease. In Cragoe EJ Jr, Kleyman TR, Simchowitz L, eds. Amiloride and its Analogs: Unique Cation Transport Inhibitors. New York, VCH Publishers Inc., 1992; pp. 301-316.

108. Kerem E, Bistritzer T, Hanukoglu A, et al. Pulmonary epithelial sodium channel dysfunction and excess airway liquid in pseudohypoaldosteronism. N Engl J Med 1999; 341: 156-162.

109. Bennett WD, Zeman KL, Foy C, et al. Effect of aerosolized uridine 5 'triphosphate on mucociliary clearance in mild chronic bronchitis. Am J Respir Crit Care Med 2001; 164: 302-306.

110. Castagnaro A, Chetta A, Forest A, D'Ippoltto R, Malorgio R, Olivieri D. Effect of sputum induction on spirometric measurements and arterial oxygen saturation in asthmatic patients, smokers, and healthy subjects. Chest 1999; 116: 941-945. 